GUEST EDITORIAL

\title{
He who refuses to obey cannot command: A guide to paediatric asthma management
}

Asthma is a heterogeneous chronic inflammatory condition characterised by airway reversibility, with variable airflow limitation. ${ }^{[1]}$ Appropriate asthma management reduces mortality and improves quality of life. Management of asthma has undergone a significant paradigm shift - from reliance on bronchodilators for symptom relief, to the introduction of inhaled corticosteroids in the early 1980s. In the new millennium, this was followed by the rapid introduction of combination agents - inhaled corticosteroids and long-acting bronchodilators. Since then, there has been an increase in the number of asthma controller medications, as well as novel biological agents for the management of asthma.

With new developments during the past 10 years, the South African Childhood Asthma Working Group (SACAWG) felt a need to review the role of a number of asthma medications to give guidance with regard to the use of these agents in the South African context. Two CME articles in this issue of SAMJ address the management of mild-to-moderate asthma in children ${ }^{[2]}$ and the place of the novel biological agents. ${ }^{[3]}$ Key to these issues is that childhood asthma can mainly be managed by primary healthcare providers and the appropriate use of inhaled corticosteroids via metered-dose inhalers with a spacer device, and the provision of reliever medication for acute exacerbations. With this approach, $>80 \%$ of children can achieve good asthma control, provided the package of care is linked to education regarding the correct technique when using asthma devices, the correct use of reliever medications and the provision of emergency care plans. This package of care must include regular follow-up visits to assess asthma control, with the need to escalate and, importantly, de-escalate therapy where appropriate.

The international literature has shown an increase in side-effects related to the over-use of systemic corticosteroids, particularly in young children with recurrent wheezing. The CME article, 'Asthma treatment in children: A pragmatic approach, ${ }^{[2]}$ provides guidance on indications for the use of systemic steroids in preschoolers and for shorter courses of systemic corticosteroids in older children with exacerbations. The current recommendation is a short course of 3 days, which differs from the recommendation in the 2009 paediatric asthma guideline. ${ }^{[4]}$

The injudicious use of macrolide antibiotics, over-the-counter bronchodilators, cough mixtures and mucolytics remains a widely prevalent problem in asthma management. The lack of evidence and potential harm regarding these therapies are emphasised. The role of biological agents, which have been widely studied in adults and with good results in specific asthma phenotypes, is addressed. There is a dearth of data on the role of most of the biological agents in children; however, most of these medications are currently not recommended in childhood asthma.

Adherence to therapy is the key to success in all chronic diseases, including asthma. It is well known that as adherence rates decline, there is loss of control of asthma, and strategies to improve this require a holistic approach. ${ }^{[5,6]} \mathrm{A}$ discussion with the child and the family, which includes a comprehensive package of behaviour modification, education and use of various tools, can improve adherence. Good asthma control in children is an attainable goal if healthcare providers adhere to guideline management and educate patients in this regard. According to an African proverb, 'Before we become leaders, we should follow', the use of guideline management should be an example of following evidencebased practice before resorting to harmful treatments. Let's first do no harm.

\section{Refiloe Masekela}

Inkosi Albert Luthuli Central Hospital and Department of Paediatrics and Child Health, College of Health Sciences, School of Clinical Medicine, University of KwaZuluNatal, Durban, South Africa masekelar@ukzn.ac.za

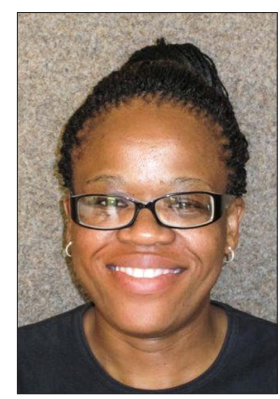

1. Global Initiative for Asthma. www.ginasthma.org (accessed 22 January 2017)

2. Masekela R, Jeevanathrum A, Kling S, et al., on behalf of the South African Childhood Asthma Working Group (SACAWG). Asthma treatment in children: A pragmatic approach. S Afr Med J 2018;108(8):612-618. https://doi.org/10.7196/SAMJ.2018.v108i8.13164

3. Masekela R, Levin M, Jeena PM, et al., on behalf of the South African Childhood Asthma Workin Group (SACAWG). Looking beyond the magic bullet: Novel asthma drugs or education, which works better? S Afr Med J 2018:108(8):619-623, https://doi.org/10.7196/SAMI.2018.v108i8.13163

4. South African Childhood Asthma Working Group. Management of chronic childhood and adolescent asthma - 2009 update. S Afr Med J 2009;9(12):898-912.

asthma -2009 update. S Afr Med J 2009;9(12):898-912.
Klok T, Kaptein AA, Brand PL. Non-adherence in children with asthma reviewed: The need for improvement of asthma care and medical education. Pediatr Allerg Immunol 2015;26(3):197-205 https://doi.org/10.1111/pai.12362

6. Makhinova T, Barner JC, Richards KM, Rascati KL. Asthma controller medication adherence, risk of exacerbation, and use of rescue agents among Texas Medicaid patients with persistent asthma. J Manag Care Spec Pharm 2015;21(12):1124-1132. https://doi.org/10.18553/jmcp.2015.21.12.1124

S Afr Med J 2018;108(8):611. DOI:10.7196/SAMJ.2018.v108i8.13406 